Conference Report

\title{
Art Images in Holistic Nursing Education
}

\author{
Cheryl V. Elhammoumi and Barbara Kellam * \\ College of Nursing, East Carolina University, Greenville, NC 27834, USA; elhammoumic@ecu.edu \\ * Correspondence: kellamb@ecu.edu; Tel.: +1-252-744-6400
}

Academic Editors: Fiona Timmins and Wilf McSherry

Received: 30 November 2016; Accepted: 22 May 2017; Published: 25 May 2017

\begin{abstract}
Background: Nursing research has concentrated on empirical knowing with little focus on aesthetic knowing. Evidence from the literature suggests that using visual art in nursing education enhances both clinical observation skills and interpersonal skills. The purpose of this review was to explore how visual art has been used in baccalaureate nursing education. Methods: Of 712 records, 13 studies met the criteria of art, nursing and education among baccalaureate nursing students published in English. Results: Three quantitative studies demonstrated statistical significance between nursing students who participated in arts-based learning compared to nursing students who received traditional learning. Findings included improved recall, increased critical thinking and enhanced emotional investment. Themes identified in 10 qualitative studies included spirituality as role enhancement, empathy, and creativity. Conclusion: Visual arts-based learning in pre-licensure curriculum complements traditional content. It supports spirituality as role enhancement in nurse training. Visual art has been successfully used to enhance both critical thinking and interpersonal relations. Nursing students may experience a greater intra-connectedness that results in better inter-connectedness with patients and colleagues. Incorporating visual arts into pre-licensure curriculums is necessary to nurture holistic nursing practice.
\end{abstract}

Keywords: visual art; baccalaureate nursing education; spirituality

The practice of the profession of nursing requires both art and science education. The art of nursing entails a strong foundation in the liberal arts that includes fine arts painting and in the humanities. The link between the arts and nursing education, however, is seldom made due to faculty needs to cover extensive course content to meet measurable objectives (Frei 2010). Nursing faculty aim to provide meaningful education that prepares nursing students for professional practice with a foundation in science and an understanding of patient care context. Incorporation of visual arts in nursing education can support those two aims in meaningful ways (Frei 2010).

\section{Background}

Using art in education is not a new idea. In the early 1900s, Lichtwark used works of art as a pedagogical tool to teach students to "see" and to perceive feelings from what they observed (Wikström 2000a). Dewey proposed that the use of art in education would aid connections between objective reality and subjective needs of people (Dewey 1958). Carper described four ways of knowing in nursing: personal, aesthetic, ethical, and empirical (Carper 1978). Personal knowing is difficult to achieve in education; aesthetic knowing is seldom pursued beyond a cursory mention of "the art of nursing" (Carper 1978). Historically, nursing research focused on developing empirical knowledge (Carper 1978). Some nursing educators have identified aesthetics as an aid to nursing students' understanding of illness and health as human conditions (Bartol 1986; Breslin 1996; Chinn 1994; Robb and Murray 1992). Darbyshire developed a course for nursing students using literature to aid in understanding caring (Darbyshire 1994a). Darbyshire used examples of Frida Kahlo's art to demonstrate how students can learn about illness cycles through observing and interpreting art 
(Darbyshire 1994b). Wikström declared that creative human caring could not develop in an education devoid of the arts and humanities (Wikström 2001). Painting, novels, poetry, and photography are all sources that can be used to depict human illness in ways that are not typically found in textbooks (Wikström 2001). The current review will focus solely on visual art images as a complement to nursing education.

The primary purpose of this paper is to explore the use of art in baccalaureate nursing education. For example, the authors explored descriptions of how have nurse educators used visual art in baccalaureate nursing programs. Literature on art images used to teach core nursing skills such as clinical observation was a primary focus of that exploration. Evidence that students connected visual art interpretations to empathic nursing practice was a secondary, but equally important, focus.

\section{Literature Review}

Two major sessions of librarian-assisted searches across multiple databases were conducted. Databases included were CINAHL, Ovid Medline, and PsycINFO. Initial advanced search terms were art therapy, art, sensory art therapies, medicine, education and nursing, and health personnel. The second librarian-assisted search used various combinations of the terms art education, health sciences, nursing students, and nursing education.

Combined, the two librarian-assisted database searches yielded a total of 712 articles. The majority of the articles were published before 2010. Therefore, the usual admonition to only consider other than classic literature published within the past five years, was suspended. This decision provided a broader understanding of what has been published about using art in nursing education. Articles focused on art therapy were eliminatedbecause there was no evidence of nursing education application. Studies of using visual art with medical students were discarded. Only English language, full text articles were selected. Figure 1 displays the selection strategy in a PRISMA flow chart. Between the years 1994 and 2009, nine research studies (six qualitative and three quantitative) and four reports of educational strategy were identified. These 13 articles will be summarized.

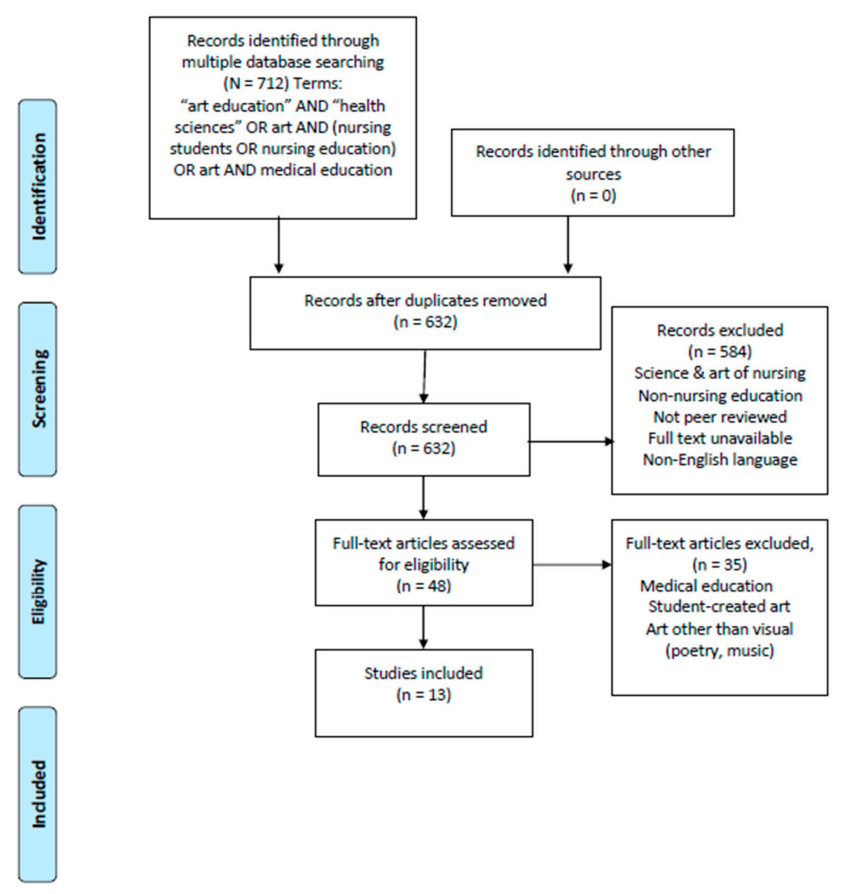

Figure 1. Art in Nursing Education Selection.

The following section is a review of significant studies using arts-based learning to engage nursing students in aesthetic learning that enhanced and deepened personal knowledge in skills needed by 
professional nurses. Arts-based learning is "a creative strategy with the potential to engage learners, foster understanding of multiple perspectives, and simultaneously connect cognitive and affective domains of learning" (Rieger and Chernomas 2013).

\section{Arts-based Studies}

Wikström has published many studies using art in nursing education and is the most prolific researcher of arts-based pedagogy included in this review. Five studies focused on arts-based pedagogy that enhanced knowledge, skills, or attitude in nursing students in several colleges of health sciences in Sweden (Wikström 2000a; Wikström 2001; Wikström 2000b; Wikström 2002; Wikström 2003). While there are similarities between the studies, each one addresses a different question. The studies are discussed chronologically.

Using a qualitative design, Wikstrom conducted an experiential learning study designed to introduce an experiential teaching-learning method in nursing education to examine interpersonal relations through art during gallery visits (Wikström 2000a). Data were generated from personal writings done by students in their third and final year of the undergraduate program. Over the 3-years of the study (1995-1998), 206 students participated in a total of 44 groups of three to seven students per group. Initially, the students were instructed to wander about the gallery, either singly or in groups, looking for a variety of relationships in the works of art before deciding on one to interpret. They were instructed to identify the themes in selected works of art, discuss them within their groups, write their findings, and then present them to the larger class group for further discussion. The students chose themes such as professional and social roles and human needs. The students were able to determine the metaphoric expressions of interpersonal relations. More than $80 \%$ of the students reported that the learning module was a success (Wikström 2000a).

Taking a phenomenological approach, Wikström implemented a visual-art program based on Van Manen's pedagogical model of problem solving and reflection (Wikström 2001). The visual-art program was combined with observations and interpretations of paintings. A study was then conducted over four years with 428 undergraduate nursing students in their first year of study (Wikström 2001). This was a visual-verbal-writing process in which a single painting reproduction was used to elicit personal knowledge of empathy. This study was done in two stages. In stage one (the problem solving phase), the students individually observed the painting and wrote their impressions. Then in stage two (the reflective phase) the students discussed whether the picture had assisted their discovery of personal knowledge of empathy. The students perceived that the (1) painting was a meaningful tool to aid expression of empathy; (2) painting was ambiguous enough to engage students' imaginations to interpret it as a nursing situation; and (3) students identified specific emotions associated with empathy (Wikström 2001).

Using a quasi-experimental design, Wikström conducted a study at two Swedish colleges of health sciences using two pre-selected works of art as a complement to theoretical knowledge in teaching nursing care (Wikström 2000b). The participants were nursing students ( $n=267)$ during the first year of a three-year program. Eight groups of students were randomized into four intervention groups $(n=121)$ and four control groups $(n=146)$. The intervention groups, divided into small group settings of two to four students, viewed two reproductions of works of visual art in a one-hour session while discussing what constituted the most typical good nursing care. The control group discussed good nursing care without the aid of the art reproduction. Data was collected from both groups using the Wheel Questionnaire, a semi-structured questionnaire. The instrument measured students' subjective perceptions of and preparedness for nursing situations by means of motivation, structure, and emotional balance. The students ranked their nursing care opinions by order of importance. Then the students labeled the opinions as negative or positive. Lastly, the students used a 3-point scale to rate the amount of control they thought they had in each of the care opinions. The results indicated that the intervention group expressed more elements of good nursing care than the control group. 
The visual art had in some way affected the students' evaluations. When compared to the control group, the students in the intervention group where more structured in their description of good nursing care. The results showed that the control group had a less clear description of good nursing care. Students in the intervention group displayed improved motivation when compared to the students in the control group ( $F=10.55, p=0.0013$ ) (Wikström 2000b).

Wikström engaged 998 students from four colleges of health sciences over two years to determine if nursing students in Sweden could predict the responses of elderly women to 12 paintings (Wikström 2002). Students came from each study year of the 3-year baccalaureate. Prior to the start of the study, an art historian had shown a group of 12 paintings to 20 randomly selected elderly women living in sheltered housing. Each of the women was interviewed to determine her art preferences. In the initial phase, the students individually observed the 12 paintings and were asked to use their intuition to determine which pictures the elderly women preferred. During the analysis phase, the students met in pairs to discuss their choices. In the synthesis phase, each student worked independently. Students wrote a report of their individual predictions describing their reflections about what which of the 12 paintings they thought the women would prefer. Student predictions and elder preferences were compared. The students successfully predicted predicting 10 out of the 12 paintings preferred by the women. The study results indicated that the students' visual art predictions were successful when compared to the elderly women's visual art preferences (Wikström 2002).

In a two-factor repeated ANOVA design, Wikström conducted a quantitative controlled intervention study using a pre-selected work of art as an empathy teaching strategy in nursing education to complement theoretical knowledge (Wikström 2003). Nursing students $(n=144)$ were randomized into an intervention group and a control group. The study was situated in a course where the students were already studying empathy. The two groups had the same pre-intevention instruction about empathy. The intervention group used a pre-selected picture to discuss empathy in nursing care from new perspectives. The control group was not exposed to the artwork. Both groups were administered the Wheel Questionnaire test instrument that measured empathy by parameters of motivation, structure, and emotional investment. Statistical analysis of the data indicated that the intervention group had more emotional investment in their engagement with learning about empathy than did the control group $(F=35.54, p=0.00001)$. The intervention group also showed a more structured engagement in learning about empathy than did the control group. Wikström identified several possible explanations for the positive effect of the visual art program. First, visual art dialogues appeared to stimulate broader conceptions of empathy. Second, the selected visual art clearly triggered debate on empathy in context of challenging nursing care situations. Third, as measured by the Wheel Inventory, visual art stimulus elicited and increased cognitive and emotional investment among nursing students (Wikström 2003).

\section{Spirituality}

Mooney and Timmins conducted focus groups to develop a teaching program using visual art to foster reflection on the concept of spirituality (Mooney and Timmins 2007). Students $(n=160)$ in the second year of their bachelor of science nursing program received the planned teaching program and one art gallery tour. Students were divided into ten groups and guided to a selection of art. Each student chose a painting they perceived as spiritual. Students wrote their subjective impressions of the paintings and reasons for selecting their choices. Later during the visit, the students returned to their selected paintings for discussions with a nurse lecturer and a gallery guide. After the gallery visit, 21 students participated in focus group interviews based on their availability and willingness to attend two pre-scheduled meetings. Five spirituality themes emerged from the focus group interviews: recognizing spiritual dimensions of everyday life; spirituality through others' impressions of art; deeper awareness of spirituality's meaning; spirituality is more than religion; and spirituality enhances a nurse's role. The results indicated that the students began to develop skills to recognize spirituality 
and spiritual needs. Self-awareness began to develop through a better understanding of others' views as well as recognizing their innate views of spirituality (Mooney and Timmins 2007).

Scaffolding is a technique commonly used in nursing education to help students build critical thinking skills. Art as scaffold was implemented at a United States public university to help beginning baccalaureate nursing students $(n=91)$ create personal expressions of nursing (Hydo et al. 2007). In this naturalistic inquiry, art was used to help students achieve greater self-awareness as they shaped professional identities. Self-awareness can be enhanced through a process of reflection followed by the support of scaffolding, which links with what was already known (Hydo et al. 2007). In the activity, students were asked to use any art form of their choice to create an expression of what nursing personally meant to them. They were given one week to consider the questions and to make their art expressions. The questions helped guide them in sharing their art creations in small groups and then in full class discussions. After the discussions, students responded to open-ended questions on what they learned about themselves through the exercise and what they learned from hearing their classmates' presentations. Data were transcribed verbatim and reviewed by two of the researchers for accuracy. All four researchers participated in detailed coding to tentatively identify categories. The data was coded individually according to the preliminary categories. The team met to discuss, compare, and revise themes to arrive at more concise categories. Then the team grouped similar categories conceptually to arrive at themes and sub-themes. Finally, the team revised definitions for all themes. Four major themes were revealed through the analysis of the narratives: (1) art and creativity; (2) teamwork; (3) boundaries and horizons within self; and (4) boundaries and horizons within the profession (Hydo et al. 2007).

The concept of scaffolding is based on Vygotsky's (1978) zone of proximal development. Vygotsky described learning functions as progressing from an embryonic stage to mature levels of learning only possible when the learner is interacting with people in the environment (Vygotsky 1978). Therefore, scaffolding provides an external support while learners internalize new knowledge. Scaffolding is removed as learners gradually become self-reliant.

Casey performed an ethnographic study using an arts-based method as a means of inquiry among baccalaureate nursing students $(n=20)$ in Dublin, Ireland (Casey 2009). This study arose from a larger research project that used arts-based methods as a means for encouraging critical thinking among nursing students. This current study focused on arts-based methods as a means of inquiry. The participants were 20 second-year undergraduate nursing students taking a nursing humanities module. Various arts-based inquiry approaches were used simultaneously. Creative writing and visual art workshops were parts of the module. Students were asked to construct an image that reflected their perceptions of a particular topic or experience. The images were shared, if desired, and discussed within the group with students sharing their perspectives on their own work and that of group members. Art-making/arts inquiry homework assignments were also given to allow the students time to reflect on personal experiences outside the group dialogical context. Data were collected from student-created visual art images, selected group discussions recorded with student permission, and researcher field notes. Student-created visual art was analyzed in conjunction with group discussions and student perceptions. Students described cognitive and emotional journeys as they constructed their art pieces. It appeared that the arts-based methods fostered personal creativity and encouraged critical thinking and inquiry among the participants. Critical inquiry and knowledge development seemed to occur through one of two main processes. The first main process was categorized as enactment of potential experience or re-enactment of actual experience. This form of internal visualization appeared to enable empathic skills, cognitive inquiry and learning. The second main process was categorized as integration of art as self/group created art. According to many of the students, self-created art helped to develop them to develop their clinical observation skills (Casey 2009).

The most recent study was conducted with non-nurse college graduate students $(n=66)$ enrolled in an accelerated master's degree nursing program (Pellico et al. 2009). Students in a medical-surgical baccalaureate nursing course were divided into 12 clinical groups. Six groups 
$(n=34)$ were selected for the Looking Is Not Seeing project. The other six groups $(n=32)$ continued to receive traditional classroom and clinical learning techniques. Those selected for the Looking Is Not Seeing activity went to a university art museum in small groups. Each student was given tools to record observations and assigned a preselected painting. The preselected paintings were chosen for their rich, visual detail. The nursing instructor and a designated art expert chose paintings that were open to alternative interpretations. The lesson emphasized that the goal was observation of the paintings, not interpretation. The students were given $10 \mathrm{~min}$ to observe the paintings and to make their notes. Students listed what they actually saw in the paintings. After $10 \mathrm{~min}$, the students gathered as a group with the nursing instructor and a docent to individually discuss their painting observations. The docent asked open-ended questions. After all students gave a thorough inventory of the visual details, they were then encouraged to consider how thoughts or feelings were communicated through visual form. The students were instructed to remain alert to all information in the paintings and not to settle too quickly on an interpretation. During the discussion, students recognized the influence of their own experiences on their analyses. This single event at the art museum lasted approximately 90 min per group of 6 students. All students $(n=66)$ then applied their observational skills to a series of six patient photographs. The photographs were sealed in individual envelopes labeled one through six. The students had five minutes to observe the picture, five minutes to write down the details, and three minutes to record a clinical interpretation of the patient presented. All students proceeded through the photographs in unison. The number and quality of observations were clustered and compared between the two groups. The data were analyzed using univariate statistics followed by Wilcoxon Mann-Whitley $\mathrm{U}$ tests and $t$ tests. The results indicated that on five out of the six photographs, students who participated in the museum activity were able to identify more signs and symptoms, list more objective clinical data, and were able to offer more alternative diagnoses when performing a differential diagnosis with a clinical picture than students who received the traditional clinical teaching $(p<0.05)$ (Pellico et al. 2009).

\section{Arts-Based Pedagogical Programs}

The art-based projects described here were not carried out as research, but as innovative student centered learning activities to enhance development into professional nurses. Each of the authors described unique ways of including aesthetic learning in the nursing curriculum.

Darbyshire participated in the development of a nursing humanities course in Glasgow, Scotland (Darbyshire 1994b). The course was offered to Registered Nurses pursuing a Bachelor of Arts with Honors Health Studies degree. This article described the section of the nursing humanities course that used Frida Kahlo's art to bring students to a deeper understanding of the complexity of human experience (Darbyshire 1994b). Examining Kahlo's work could open new ways of thinking, learning, and understanding of lived experiences of human suffering (Darbyshire 1994b). Kahlo's self-portraits of her multiple spinal surgeries, several miscarriages and chronic pain provide empathy enhancing learning experiences.

Innskeep and Lisko described an alternative learning activity to teach nursing diagnosis in an art gallery (Innskeep and Lisko 2001). The students had studied nursing diagnoses, but struggled with identifying any diagnosis except for the most obvious one. The authors visited a local museum to introduce their ideas to the director and staff. Thirteen works of art were selected to meet the varying student interests across schools of art movements, i.e., impressionism, classical realism, neo-expressionism. The selected paintings represented a variety of nursing diagnoses. The students were given a list of diagnoses from the North American Nursing Diagnosis Association. After arriving at the museum, the students were instructed to view the art as they would view a patient and assign nursing diagnoses. They were given approximately two hours to tour the museum and interpret the 13 selected works of art. During post conference, the students began to grasp how assessing data and grouping it together could lead to making a nursing diagnosis. Students perceived that more than one interpretation was possible by viewing data from different perspectives. Without fear 
of criticism, the students' freedom of expression allowed them to expand their ability to interpret clinical data. The faculty concluded that the activity reinforced concepts taught in the classroom (Innskeep and Lisko 2001).

Pardue used an art gallery as an innovative setting to teach health assessment in an RN-to-BSN course (Pardue 2005). She collaborated with the director of a university based art gallery to develop guided observational worksheets to be used in the course. Painting, photography, and sculpture were all used in this laboratory experience. Students were guided by the work sheets and instructions to visualize the elements in art of line, color, light, texture, and shape and symmetry and to link the same to inspection of the human body. The students were able to use the art to practice assessment skills on subjects other than healthy fellow students in the traditional laboratory. Students usually required 30 to $60 \mathrm{~min}$ to view the artwork and discuss their observations with their partners. Immediately following the activity in the gallery, the students reconvened as a class for debriefing and reflection. The students observed that just as a bold line in a painting can draw attention away from peripheral features, so could obvious distortions in the human body draw attention away from other important assessment details. Discussion of the art with others aided the realization of other possible perspectives. They linked this to working with interdisciplinary teams for comprehensive assessment of patients. According to the students, viewing the art encouraged their own reflections about how they examined individuals.

Frei integrated the humanities as part of an innovative clinical experience (Frei 2010). The students were assigned to observe and discuss five works of art after they had been introduced to formal art analysis comprised of precise observation from near and far perspectives. At the end of the guided museum experience, students were instructed to choose one of the works of art to describe. They were asked to explain how discussion about the art applied to a clinical objective or a patient experience. This art experience was used to improve observation and communication skills, narrative sequencing abilities, and empathy (Frei 2010).

\section{Summary}

The reports of innovative teaching techniques described in this review focused on the use representational art as a pedagogical tool. The art acted as a bridge to connect students to one another and the teacher/researcher to the students. The art has also been likened to a vehicle that brings the students to greater aesthetic knowing that can influence self-awareness. Art as a tool has also been used as scaffolding to aid deeper learning. Personal knowing has the potential to deepen from the expanding self-awareness gained from engaging in the aesthetic. Researchers have used the tool of art in varying locations: classrooms, university art galleries, and major public museums. Art has been incorporated in learning activities in a semester-long nursing humanities course, modules within already established courses, and as alternative clinical or laboratory experiences. The participants have been nursing students ranging from first year of study to final year, non-nurse accelerated nursing program participants, to Registered Nurses returning to school in an honors baccalaureate program. The research results revealed some beneficial impact of art on components critical to nursing skills, attitude, and knowledge development.

\section{Conclusions}

Arts-based learning is an appropriate approach to use with contemporary students who are accustomed to media and technology in their learning experiences. Nurse educators must assist students to become caring, holistic professionals. Multiple aspects of professional nursing have been reported as being positively impacted by inclusion of arts-based learning in nursing education. Of particular interest is the outcome of increased empathy and emotional investment among nursing students exposed to visual art. Such exposure may help nursing students acquire inter-connectedness to their patient encounters. Additionally, exploration of visual art may help nursing students develop a more cohesive inner awareness, or intra-connectedness. Clearly, baccalaureate nursing education requires multi-modal approaches. 
Author Contributions: Cheryl V. Elhammoumi conceived the idea for the literature review as part of a doctoral program. Barbara Kellam guided development of the review manuscript, co-wrote and revised the paper several times.

Conflicts of Interest: The authors declare no conflict of interest.

\section{References}

Bartol, Genevieve. 1986. Using humanities in nursing education. Nurse Educator 11: 21-23. [CrossRef] [PubMed] Breslin, Eileen. 1996. Aesthetic methods as a means of knowing for nursing. Issues in Mental Health Nursing 17: 503-5. [CrossRef] [PubMed]

Carper, Barbara. 1978. Fundamental Patterns of Knowing in Nursing. Advanced Nursing Science 1: 13-23. [CrossRef]

Casey, Briege. 2009. Arts-based inquiry in nursing education. Contemporary Nurse 32: 69-82. [CrossRef] [PubMed]

Chinn, Peggy. 1994. Developing a method for aesthetic knowing in nursing. In Art and Aesthetics in Nursing. Edited by Peggy L. Chinn and Jean Watson. New York: National League for Nursing, pp. 19-40.

Darbyshire, Philip. 1994a. Understanding caring through arts and humanities: A medical/nursing humanities approach to promoting alternative experiences of thinking and learning. Journal of Advanced Nursing 19: 856-63. [CrossRef]

Darbyshire, Philip. 1994b. Understanding the life of illness: Learning through the art of Frida Kahlo. Advances in Nursing Science 17: 51-59. [CrossRef]

Dewey, John. 1958. Art as Experience. New York: Capricorn Books G.P. Put.

Frei, Judith. 2010. Ways of seeing: Using the visual arts in nursing education. Journal of Nursing Education 49: 672-76. [CrossRef] [PubMed]

Hydo, Sharon K., Diane Marcyjanik, CeCilia Zorn, and Michelle Hooper. 2007. Art as a scaffolding teaching strategy in baccalaureate nursing education. International Journal of Nursing Education Scholarship 4: 1-13. [CrossRef] [PubMed]

Innskeep, Sandra, and Susan Lisko. 2001. Alternative clinical nursing experience in an art gallery. Nurse Educator 26: 117-19. [CrossRef]

Mooney, Brona, and Fiona Timmins. 2007. Spirituality as a universal concept: Student experience of learning about spirituality through the medium of art. Nurse Education in Practice 7: 275-84. [CrossRef] [PubMed]

Pardue, Karen. 2005. Blending aesthetics and empirics: Teaching health assessment in an art gallery. Journal of Nursing Education 44: 334-37. [PubMed]

Pellico, Linda Honan, Linda Friedlaender, and Kristopher Fennie. 2009. Looking is not seeing: Using art to improve observational skills. Journal of Nursing Education 48: 648-53. [CrossRef] [PubMed]

Rieger, Kendra, and Wanda M. Chernomas. 2013. Arts-based learning: Analysis of the concept for nursing education. International Journal of Nursing Education Scholarship 10: 1-10. [CrossRef] [PubMed]

Robb, Joy, and Rowena Murray. 1992. Medical humanities in nursing: Thought provoking. Journal of Advanced Nursing 17: 1182-87. [CrossRef] [PubMed]

Vygotsky, Lev Semyonovich. 1978. Mind in Society: The Development of Higher Psychological Processes. Cambridge: Harvard University Press.

Wikström, Brit-Maj. 2000a. Nursing education at an art gallery. Journal of Nursing Scholarship 32: 197-99. [CrossRef]

Wikström, Brit-Maj. 2000b. Works of Art: A complement to theoretical knowledge when teaching nursing care. Journal of Clinical Nursing 10: 25-32. [CrossRef]

Wikström, Brit-Maj. 2001. Work of art dialogues: An educational technique by which students discover personal knowledge of empathy. International Journal of Nursing Practice 7: 24-29. [CrossRef] [PubMed]

Wikström, Brit-Maj. 2002. Intuition and visual art: Student nurses' projection into experiences of elderly women. The Australian Journal of Holistic Nursing 9: 24-31. [PubMed]

Wikström, Brit-Maj. 2003. A picture of a work of art as an empathy teaching strategy in nursing education complementary to theoretical knowledge. Journal of Professional Nursing 19: 49-54. [CrossRef] [PubMed] 